\title{
Peritoneal Dialysis Catheter Infection
}

National Cancer Institute

\section{Source}

National Cancer Institute. Peritoneal Dialysis Catheter Infection. NCI Thesaurus. Code C114725.

A local or systemic infection associated with the use of a peritoneal dialysis catheter. 